Research Paper

\title{
Distribution of Cytotoxic T Lymphocyte-Associated Antigen-4 Promoter Polymorphisms in Taiwanese Patients with Type 2 Diabetes Mellitus
}

\author{
Yung-Luen Shih ${ }^{1,2,3 \dagger}$, Hsu-Feng Lut, Chiao-Wan Hsiao, ${ }^{5,6^{*}}$, Kuo-Ting Ho ${ }^{6,7^{*}}$, Pei-Chi Chen ${ }^{8}$, Chien-Ning \\ Huang 9,10, Yuanmay Chang ${ }^{11}$, Shang-Jyh Kao ${ }^{12}$, Ming-Yuh Shiau ${ }^{13 凶}$ and Yih-Hsin Chang ${ }^{6}$ \\ 1. Department of Pathology and Laboratory Medicine, Shin Kong Wu Ho-Su Memorial Hospital, Taipei, \\ 2. School of Medical Laboratory Science and Biotechnology, Taipei Medical University, Taipei, \\ 3. School of Medicine, College of Medicine, Fu-Jen Catholic University, New Taipei City, \\ 4. Department of Clinical Pathology, Cheng Hsin General Hospital, Taipei, \\ 5. Program in Molecular Medicine, National Yang-Ming University and Academia Sinica, Taipei, \\ 6. Department of Biotechnology and Laboratory Science in Medicine, National Yang-Ming University, Taipei, \\ 7. Hi-Q Clinical Laboratory, Quanzhou, Fujian Province, PRC, \\ 8. Divisions of Endocrinology and Metabolism, Shin Kong Wu Ho-Su Memorial Hospital, Taipei, \\ 9. Department of Internal Medicine, Chung Shan Medical University Hospital, Taichung, \\ 10. School of Medicine, Chung Shan Medical University, Taichung, \\ 11. Department of Long Term Care, MacKay Medical College, New Taipei City, \\ 12. Pulmonary Division, Shin Kong Wu Ho-Su Memorial Hospital, Taipei, \\ 13. Department of Nursing, College of Nursing, Hungkuang University, Taichung, Taiwan \\ t Equal contributions as the $1^{\text {st }}$ authors \\ * Equal contributions as the $3^{\text {rd }}$ authors
}

$\triangle$ Corresponding authors: Ming-Yuh Shiau, PhD, Associate Professor, Department of Nursing, College of Nursing, Hungkuang University, Taichung 433, Taiwan. Tel: 886-4-26318652 ext. 7090; Fax: 886-4-26311198; E-mail: ming@hk.edu.tw. Yih-Hsin Chang, PhD, Professor, Department of Biotechnology and Laboratory Science in Medicine, National Yang-Ming University, Taipei 112, Taiwan. Tel: 886-2-28267955; Fax: 886-2-28219240; E-mail: cyh@ym.edu.tw

(1) Ivyspring International Publisher. This is an open access article distributed under the terms of the Creative Commons Attribution (CC BY-NC) license (https://creativecommons.org/licenses/by-nc/4.0/). See http://ivyspring.com/terms for full terms and conditions.

Received: 2017.09.29; Accepted: 2018.01.05; Published: 2018.02.12

\begin{abstract}
Type 2 diabetes mellitus (T2DM) is associated with chronic inflammation, suggesting the metabolic abnormalities are originated from or exacerbated by cytokine overproduction. Cytokines and counter-regulatory molecules are crucial in keeping the balance of immune responses and, therefore, are potential candidates involved in T2DM etiology, development and complications. Our previous reports identify several significant associations between the genotypes of cytokine genes and T2DM and/or the clinical lipid parameters, which strongly suggest the participation of immune-regulatory molecules in lipid metabolism. The aim of this study is to determine the distribution of gene encoding cytotoxic $T$ lymphocyte-associated antigen-4 (CTLA-4), a T-cell negative regulator, in T2DM patients and health subjects. Genomic DNA was extracted from 287 Taiwanese T2DM patients and 278 ethnic- and agematched healthy subjects, and two CTLA-4 polymorphisms $(-318 \mathrm{C} / \mathrm{T}$ and $+49 \mathrm{~A} / \mathrm{G})$ were analyzed by polymerase chain reaction-restriction fragment length polymorphism. Intriguingly, CTLA-4 -318 genotype was associated with circulatory triglycerides in T2DM subjects $(P=0.019)$ although no significant association between CTLA-4 $-318(P=0.119)$ and $+49(P=0.2)$ genotypes with T2DM was identified. In addition, CTLA-4 +49 genotype was significantly associated with the ratio between total cholesterol and high-density lipoprotein $(P=0.004)$ in control subjects. Our results suggest that CTLA-4 may be involved in lipid metabolism and affect T2DM disease progression and/or the development of diabetic complications although this gene does not represent a major risk factor for T2DM.
\end{abstract}

Key words: type 2 diabetes mellitus; cytotoxic T lymphocyte-associated antigen-4; genetic polymorphisms

\section{Introduction}

Type 2 diabetes mellitus (T2DM) is the most common form of diabetes characterized by abnormally high blood glucose. People with risk factors such as dyslipidemia, impaired glucose 
tolerance, and hypertension (so-called metabolic syndrome) are susceptible to develop T2DM. The global prevalence of diabetes is estimated to reach $4.4 \%$ with more than 350 million affected people in year 2030 [1]. The prevalence of T2DM varies among different ethnic populations, with the highest rate found in Pima Indians (as high as 50\%) [2]. In Taiwan, more than $98 \%$ of diabetic patients are characterized as T2DM [3], affecting more than 1 million individuals.

The etiology of T2DM is still an enigma although insulin resistance is the major characteristics. Genetic and environmental factors are the study focus of T2DM etiology, and linkage studies have localized some of the genes that influence the development of this disorder. Cytokines and counter-regulatory molecules are crucial in the regulation of immune responses and, therefore, are potential candidates involved in T2DM etiology. Evidence regarding cytokine gene polymorphisms among T2DM patients is increasing, however, with conflicting and inconclusive observations [4].

Cytotoxic $\mathrm{T}$ lymphocyte-associated antigen- 4 (CTLA-4), a negative regulator of $\mathrm{T}$ cell activation and proliferation, plays important roles in regulating immune surveillance and responses [5]. Abundant evidence has documented the association of several single nucleotide polymorphisms (SNPs) of the CTLA-4 gene and autoimmune diseases such as type 1 diabetes mellitus [6-10]. Nevertheless, the putative association between CTLA-4 and the more prevalent T2DM does not cause much attention. Only very limited reports with contradictory conclusions regarding the study of CTLA-4 and T2DM are documented [11-14]. The discrepancy indicates that unique genetic characteristics may be involved in T2DM pathogenesis among different ethnic population [15]. Therefore, it is tempting to identify whether the CTLA-4 SNPs would contribute to T2DM pathogenesis and/or clinical manifestations in Taiwan. To inspect this hypothesis, the frequencies of the CTLA-4 SNPs (-318C/T and +49A/G) among patients with T2DM as well as the association of these polymorphisms with patients' biochemical features were examined in Taiwanese population.

\section{Materials \& Methods}

\section{Study subjects}

Whole blood samples of 278 Taiwanese patients with T2DM were obtained from the Divisions of Endocrinology and Metabolism and the Department of Pathology and Laboratory Medicine, Shin Kong Wu Ho-Su Memorial Hospital, Taipei. For reference, control population consisted of 287 unrelated, ethnic- and age- matched non-diabetic healthy subjects were recruited from Shin Kong Wu Ho-Su Memorial Hospital, Taipei, by selecting those with normal blood glucose. The diagnosis of T2DM was based on the clinical characteristics, magnitude of residual insulin or C-peptide secretory responses. Information about patients' clinical biochemical manifestations were listed in Table 1. Informed consent from each study subject was obtained after the nature of study was fully explained. The study was approved by the Ethics Review Committee of Shin Kong Wu Ho-Su Memorial Hospital.

Table 1. Demographic and biochemical data of study subjects in this study

\begin{tabular}{|c|c|c|c|}
\hline & $\begin{array}{l}\text { Control } \\
(\mathbf{n}=287)^{\dagger}\end{array}$ & $\begin{array}{l}\text { T2DM } \\
(\mathbf{n}=278)^{\dagger}\end{array}$ & $P^{\dagger}$ \\
\hline HbA1c (\%) & $5.54 \pm 0.32$ & $8.18 \pm 2.24$ & $<0.001$ \\
\hline Fasting glucose $(70-110 \mathrm{mg} / \mathrm{dL})^{*}$ & $87.52 \pm 7.95$ & $148.3 \pm 59.96$ & $<0.001$ \\
\hline $\operatorname{ALT}(<40 \mathrm{U} / \mathrm{L})^{*}$ & $38.36 \pm 23.26$ & $32.1 \pm 27.93$ & $<0.001$ \\
\hline HDL-C $(>35 \mathrm{mg} / \mathrm{dL})^{*}$ & $52.38 \pm 13.53$ & $45.76 \pm 15.87$ & $<0.001$ \\
\hline LDL-C $(<160 \mathrm{mg} / \mathrm{dL})^{*}$ & $118.55 \pm 29.26$ & $100.34 \pm 32.50$ & $<0.001$ \\
\hline Triglycerides $(20-200 \mathrm{mg} / \mathrm{dL})^{*}$ & $118.49 \pm 67.38$ & $214.25 \pm 486.09$ & $<0.001$ \\
\hline Cholesterol $(125-240 \mathrm{mg} / \mathrm{dL})^{*}$ & $193.98 \pm 32.85$ & $185.09 \pm 63.09$ & $<0.001$ \\
\hline CHO/HDL & $2.78 \pm 2.00$ & $1.97 \pm 0.82$ & $<0.001$ \\
\hline Creatinine $(0.6-1.4 \mathrm{mg} / \mathrm{dL})^{*}$ & $0.80 \pm 0.18$ & $0.91 \pm 0.41$ & 0.016 \\
\hline
\end{tabular}

Data were presented as mean \pm standard deviation.

${ }^{*}$ Numbers in parenthesis indicated the normal reference range of each biochemical test.

†Mann-Whitney test.

\section{Biochemical analysis}

Serum samples from the study subjects were isolated and subjected to analysis by automated biochemical analyzers, including fasting glucose, cholesterol (CHO), triglycerides (TGs), high density lipoprotein (HDL), low-density lipoprotein (LDL), creatinine, alanine aminotransferase (ALT) [by AU680/AU5800, Beckman Coulter, USA] and glycosylated hemoglobin HbA1c [by HLC-723 G8, Tosoh, Japan]. CHO/HDL was calculated and documented as ratio by levels of $\mathrm{CHO}$ over HDL.

\section{CLTA-4 genotyping}

CTLA-4 genotyping were conducted as described [16]. Genomic DNA was extracted from peripheral blood mononuclear cells using GenoMaker commercial kit (GenePure Technology, Taiwan). Amplification of +49 and -318 fragments was performed in a volume of $30 \mu \mathrm{L}$ containing $100 \mathrm{ng}$ of template DNA, $10 \mathrm{mmol} / \mathrm{L}$ Tris- $\mathrm{HCl}$ (pH9.0), $50 \mathrm{mM}$ $\mathrm{KCl}, 3 \mathrm{mM} \mathrm{MgCl} 2,0.01 \%$ gelatin and $0.1 \%$ Triton $\mathrm{X}-100,50 \mu \mathrm{M}$ dNTP, $0.5 \mu \mathrm{M}$ of each primer (as listed in Table 2) and 1 unit GeneTaq DNA polymerase (GenePure Technology, Taiwan). The parameters for thermocycling were as followings: an initial denaturation at $95^{\circ} \mathrm{C}$ for 5 minutes, followed by 30 
cycles of denaturation at $95^{\circ} \mathrm{C}$ for $1 \mathrm{~min}$; annealing at $55^{\circ} \mathrm{C}$ for $1 \mathrm{~min}$; extension at $72^{\circ} \mathrm{C}$ for $1 \mathrm{~min}$; and followed by final extension at $72^{\circ} \mathrm{C}$ for 5 minutes. Identification of the 2 alleles at +49 and -318 polymorphic sites was performed by incubating PCR product with $B b v I$ and Mse I, respectively, followed by electrophoresis.

Table 2. Primer sequences used for the detection of genetic polymorphisms.

\begin{tabular}{|c|c|c|c|}
\hline Genotypes & Primer sequence & $\begin{array}{l}\text { Restriction } \\
\text { enzyme }\end{array}$ & $\begin{array}{l}\text { PCR product } \\
\text { (bps) }\end{array}$ \\
\hline \multicolumn{4}{|l|}{ CTLA-4 } \\
\hline$-318 \mathrm{C}>\mathrm{T}$ & $\begin{array}{l}5^{\prime} \text { - AATGAATTGGACTGGATGG } \\
-3^{\prime} \\
5^{\prime} \text {-TTACGAGAAAGGAAGCCGTG } \\
-3^{\prime}\end{array}$ & Mse I & 247 \\
\hline$+49 \mathrm{~A}>\mathrm{G}$ & $\begin{array}{l}\text { 5'-CCACGGCTTCCTTTCTCGTA-3' } \\
5^{\prime} \text { AGTCTCACTCACCTTTGCAG-3' }\end{array}$ & $B b v \mathrm{I}$ & 329 \\
\hline
\end{tabular}

\section{Statistical analysis}

Data analysis started with descriptive statistics, including mean and standard deviation for continuous variables, and frequency for categorical variables. If necessary, natural logarithm transformation was used to enhance normality for blood biochemistry parameters with skewed distribution. Mann-Whitney test was applied for comparisons of each of the blood biochemistry parameters between diabetic and controls subjects, and Chi-square test for comparing frequencies of different genotypes and alleles between groups. Moreover, student's $t$-test and non-parametric Kruskal Wallis test were applied to compare means of respective blood biochemistry parameters among subjects with different CTLA-4 genotypes, respectively. The statistical software of SPSS software was applied for the analyses. Statistical differences were defined as $P<0.05$ for all statistical tests.

\section{Results}

\section{Distribution of CTLA-4 genotypes among the study subjects}

The present study aimed at investigating the distribution of CTLA-4 genetic polymorphisms among the healthy subjects and T2DM patients. Detail information about the clinical biochemical manifestations among the study subjects were listed in Table 1. Significant differences of all the biochemical data were identified between the control and T2DM subjects.

Table 3 showed the distribution of CTLA-4 genotyping results among the study subjects. In non-diabetic control individuals, 215 (74.9\%), 67
(23.3\%) and 5 (1.7\%) carried CTLA-4 -318 C/C, heterologous $\mathrm{C} / \mathrm{T}$ and $\mathrm{T} / \mathrm{T}$ genotype, respectively. In T2DM patients, $227(81.7 \%), 49(17.9 \%)$ and $2(0.7 \%)$ carried $\mathrm{C} / \mathrm{C}, \mathrm{C} / \mathrm{T}$ and $\mathrm{T} / \mathrm{T}$ genotype, respectively. The prevalence of $-318^{*} \mathrm{C}$ and $-318^{*} \mathrm{~T}$ allele in control individuals was $86.6 \%$ and $13.4 \%$, respectively; and the corresponding frequencies in T2DM patients was $90.3 \%$ and $9.7 \%$. No significant difference of CTLA-4 -138 genotypic distribution between subject groups was identified $(P=0.119)$, while marginal significance was observed in the CTLA-4 -318 allelic distribution $(P=0.063)$.

In terms of the CTLA-4 +49 polymorphisms (Table 3), 36 (12.5\%), 150 (52.3\%) and 101 (35.3\%) control subjects carried A/A, heterologous $\mathrm{A} / \mathrm{G}$ and $\mathrm{G} / \mathrm{G}$ genotype, respectively. In patients with T2DM, $33(11.9 \%), 127(45.7 \%)$ and 118 (42.4\%) carried A/A, $\mathrm{A} / \mathrm{G}$ and $\mathrm{G} / \mathrm{G}$ genotype, respectively. The prevalence of $+49^{*} \mathrm{~A}$ and $+49^{*} \mathrm{G}$ alleles in control individuals was $38.7 \%$ and $61.3 \%$, respectively; and that in T2DM counterpart was $34.7 \%$ and $65.3 \%$. Neither the CTLA-4 +49 genotypic $(P=0.2)$ nor allelic $(P=0.175)$ distribution between subject groups showed significant differences.

Table 3. Frequencies of genotypic polymorphisms in T2DM patients and control subjects.

\begin{tabular}{llll}
\hline & $\begin{array}{l}\text { Control } \\
\mathbf{n}(\%)\end{array}$ & $\begin{array}{l}\text { T2DM } \\
\mathbf{n}(\%)\end{array}$ & $P^{\dagger}$ value \\
\hline CTLA-4 -318C/T & $\mathrm{n}=287$ & $\mathrm{n}=278$ & \\
C/C & $215(74.9)$ & $227(81.7)$ & 0.119 \\
C/T & $67(23.3)$ & $49(17.9)$ & \\
T/T & $5(1.7)$ & $2(0.7)$ & \\
C allele & $497(86.6)$ & $502(90.3)$ & 0.063 \\
T allele & $77(13.4)$ & $54(9.7)$ & \\
& & & \\
CTLA-4 +49A/G & $\mathrm{n}=287$ & $\mathrm{n}=278$ & \\
A/A & $36(12.5)$ & $33(11.9)$ & \\
A/G & $150(52.3)$ & $127(45.7)$ & \\
G/G & $101(35.2)$ & $118(42.4)$ & \\
A allele & $222(38.7)$ & $193(34.7)$ & \\
G allele & $352(61.3)$ & $363(65.3)$ & \\
"Number in the parentheses indicated the percentage. \\
tChi-square test. \\
\end{tabular}

\section{Association of CTLA-4 genotypes with triglycerides and the ratio of total cholesterol to high-density lipoprotein cholesterol}

The correlation between study subjects' biochemical manifestations with their genotypes was subsequently analyzed. For CTLA-4 -318 polymorphisms (Table 4), significant association between the genotypes with TGs was identified in T2DM patients $(P=0.019)$. In addition, a tendency reaching significant association between CTLA-4 -318 genotypes with fasting glucose $(P=0.069)$ and $\mathrm{CHO} / \mathrm{HDL}(P=0.067)$ was observed in control subjects. As for +49 SNPs 
(Table 5), significant association between genotypes with the ratio of total $\mathrm{CHO}$ to HDL-C (CHO/HDL) was identified in healthy subjects $(P=0.004)$. Besides, marginal significance between genotypes and ALT was noticed $(P=0.063)$. Nevertheless, no significant association between +49 genotypes and the biochemical parameters in the T2DM patients was found.

Table 4. Associations between CTLA-4 -318 genotypes and clinical parameters

\begin{tabular}{|c|c|c|c|c|}
\hline \multirow[t]{2}{*}{ Parameter } & \multicolumn{3}{|l|}{ Genotype } & \multirow[t]{2}{*}{$P \dagger$} \\
\hline & $\mathrm{C} / \mathrm{C}$ & $\mathrm{C} / \mathrm{T}$ & $\mathrm{T} / \mathrm{T}$ & \\
\hline \multicolumn{5}{|l|}{ Control } \\
\hline $\mathrm{HbA1c}$ & $5.52 \pm 0.33$ & $5.62 \pm 0.27$ & $5.48 \pm 0.29$ & 0.070 \\
\hline Fasting glucose & $87.15 \pm 8.19$ & $88.98 \pm 7.17$ & $83.80 \pm 5.07$ & 0.069 \\
\hline ALT & $37.46 \pm 20.08$ & $40.83 \pm 31.9$ & $44.00 \pm 11.85$ & 0.687 \\
\hline HDL-C & $52.27 \pm 12.78$ & $52.39 \pm 12.78$ & $56.80 \pm 21.88$ & 0.917 \\
\hline LDL-C & $116.76 \pm 29.32$ & $125.27 \pm 28.17$ & $105.20 \pm 31.32$ & 0.149 \\
\hline Triglycerides & $118.73 \pm 68.32$ & $118.06 \pm 64.49$ & $113.80 \pm 79.12$ & 0.873 \\
\hline Cholesterol & $192.15 \pm 31.5$ & $200.49 \pm 36.36$ & $185.40 \pm 35.40$ & 0.455 \\
\hline $\mathrm{CHO} / \mathrm{HDL}$ & $2.86 \pm 2.19$ & $2.45 \pm 1.16$ & $3.72 \pm 1.86$ & 0.067 \\
\hline Creatinine & $0.80 \pm 0.18$ & $0.80 \pm 0.19$ & $0.86 \pm 0.22$ & 0.815 \\
\hline \multicolumn{5}{|l|}{ T2DM } \\
\hline HbA1c & $8.21 \pm 2.27$ & $8.09 \pm 2.16$ & $7.50 \pm 0.56$ & 0.919 \\
\hline Fasting glucose & $148.74 \pm 61.07$ & $146.41 \pm 55.95$ & $144.00 \pm 48.08$ & 0.85 \\
\hline ALT & $32.48 \pm 29.81$ & $29.81 \pm 16.28$ & $40.00 \pm 42.43$ & 0.836 \\
\hline HDL-C & $45.12 \pm 13.96$ & $48.74 \pm 22.86$ & $45.00 \pm 5.66$ & 0.337 \\
\hline LDL-C & $100.19 \pm 32.30$ & $101.96 \pm 34.07$ & $77.50 \pm 0.71$ & 0.459 \\
\hline Triglycerides & $230.72 \pm 535.16$ & $137.76 \pm 93.21$ & $227.5 \pm 92.63$ & 0.019 \\
\hline Cholesterol & $186.63 \pm 66.60$ & $175.96 \pm 42.31$ & $235.00 \pm 70.72$ & 0.231 \\
\hline $\mathrm{CHO} / \mathrm{HDL}$ & $2.00 \pm 0.86$ & $1.82 \pm 0.52$ & $3.05 \pm 0.92$ & 0.093 \\
\hline Creatinine & $0.92 \pm 0.40$ & $0.90 \pm 0.43$ & $0.64 \pm 0.08$ & 0.331 \\
\hline
\end{tabular}

Table 5. Associations between CTLA- $4+49$ genotypes and clinical parameters

\begin{tabular}{|c|c|c|c|c|}
\hline \multirow[t]{2}{*}{ Parameter } & \multicolumn{3}{|l|}{ Genotype } & \multirow[t]{2}{*}{$P \dagger$} \\
\hline & A/A & A/G & G/G & \\
\hline \multicolumn{5}{|l|}{ Control } \\
\hline HbA1c & $5.50 \pm 0.39$ & $5.57 \pm 0.30$ & $5.52 \pm 0.32$ & 0.375 \\
\hline Fasting glucose & $89.19 \pm 5.67$ & $87.47 \pm 7.44$ & $86.99 \pm 9.26$ & 0.609 \\
\hline ALT & $29.83 \pm 15.74$ & $39.23 \pm 25.68$ & $40.13 \pm 21.18$ & 0.063 \\
\hline HDL-C & $53.99 \pm 15.11$ & $51.29 \pm 12.97$ & $53.42 \pm 13.75$ & 0.402 \\
\hline LDL-C & $127.39 \pm 34.14$ & $118.82 \pm 28.68$ & $114.96 \pm 27.81$ & 0.082 \\
\hline Triglycerides & $108.19 \pm 49.70$ & $123.47 \pm 71.89$ & $114.75 \pm 65.81$ & 0.543 \\
\hline Cholesterol & $202.11 \pm 40.23$ & $194.27 \pm 31.60$ & $190.64 \pm 31.55$ & 0.313 \\
\hline $\mathrm{CHO} / \mathrm{HDL}$ & $2.25 \pm 1.17$ & $2.82 \pm 2.52$ & $2.90 \pm 1.19$ & 0.004 \\
\hline Creatinine & $0.77 \pm 0.17$ & $0.81 \pm 0.19$ & $0.80 \pm 0.17$ & 0.733 \\
\hline \multicolumn{5}{|l|}{ T2DM } \\
\hline HbA1c & $8.33 \pm 2.26$ & $8.12 \pm 2.40$ & $8.21 \pm 2.06$ & 0.441 \\
\hline Fasting glucose & $147.42 \pm 58.61$ & $149.88 \pm 59.13$ & $146.83 \pm 61.65$ & 0.881 \\
\hline ALT & $28.67 \pm 27.04$ & $32.90 \pm 27.52$ & $32.12 \pm 28.79$ & 0.309 \\
\hline HDL-C & $43.70 \pm 11.29$ & $45.26 \pm 13.68$ & $46.87 \pm 18.92$ & 0.871 \\
\hline LDL-C & $97.42 \pm 31.91$ & $101.35 \pm 35.27$ & $100.08 \pm 29.65$ & 0.775 \\
\hline Triglycerides & $229.18 \pm 316.78$ & $166.89 \pm 134.34$ & $261.45 \pm 714.23$ & 0.426 \\
\hline Cholesterol & $187.97 \pm 54.48$ & $180.95 \pm 69.77$ & $188.78 \pm 57.7$ & 0.139 \\
\hline $\mathrm{CHO} / \mathrm{HDL}$ & $2.09 \pm 0.99$ & $1.90 \pm 0.72$ & $2.01 \pm 0.86$ & 0.394 \\
\hline Creatinine & $0.86 \pm 0.28$ & $0.88 \pm 0.36$ & $0.96 \pm 0.48$ & 0.759 \\
\hline
\end{tabular}

*The data were presented as the mean \pm SEM

tNonparametric statistics: Kruskal Wallis test
Combining the results regarding the significant association between CTLA-4 -318 SNPs with triglyceride in T2DM patients and CTLA-4 +49 SNPs with $\mathrm{CHO} / \mathrm{HDL}$ in control subjects, it suggests that CTLA-4 may play certain role in regulating lipid metabolism.

\section{Discussion}

T2DM is associated with chronic inflammation. Diabetic patients with long duration are susceptible to develop multiple complications. Pickup et al. first discovered that blood concentrations of acute-phase response markers in circulation of type 2 diabetic patients are increased [3]. Accumulating evidence demonstrates that diabetes is associated with enhanced cytokine production, suggesting the metabolic abnormalities are originated from or exacerbated by cytokine overproduction [17-20]. Cytokines and counter-regulatory molecules are crucial in keeping the balance of immune responses and, therefore, are potential candidates involved in T2DM etiology, development and complications. IL-1, IL-6 and TNF- $\alpha$ are known to trigger the elevation of inflammatory markers, which demonstrates that control of $\mathrm{T}$ cell proliferation and activation might be one of the important factors in T2DM pathogenesis. Moreover, our previous reports reveal several significant associations between genotypes of the cytokine genes and T2DM and/or the clinical lipid profiles, including (1) IL-4 and IL-10 with T2DM [15,21]; (2) IL-4, IL-4Ra and TNF-a with HDL-C $[15,22,23]$; and (3) TNF-a with fasting glucose levels [22]. Collectively, these results strongly suggest that the immune-regulatory molecules are involved in diabetic development and lipid metabolism.

CTLA-4 is a transmembrane glycoprotein which acts as a co-stimulatory molecule in regulating $\mathrm{T}$ cell activation [24-27]. More than $100 \mathrm{SNPs}$ in the gene encoding CTLA-4 are implicated in the regulation of its expression and/or activity. Among the CTLA-4 SNPs, $+49 \mathrm{~A} / \mathrm{G}$ and $-318 \mathrm{C} / \mathrm{T}$ are implicated in several diseases, such as Graves' disease [28,29], type 1 diabetes $[13,28,30,31]$, systemic lupus erythematosus [32], Hashimoto thyroiditis [33], Addison's disease [34], T2DM [14] and malignancies [35-37]. Wang et al. reported that CTLA-4 $-318^{*} \mathrm{~T}$ allele may contribute to CTLA-4 upregulation [38]. Another study suggested that patients carrying $+49^{*} \mathrm{G}$ allele and thus having higher soluble CTLA-4 levels had a lower incidence of acute rejection in liver transplantation [39]. However, the association between CTLA-4 SNPs and promoter activity is still controversial since Ligers et al. reported that individuals carrying CTLA-4 $-318^{*} \mathrm{~T}$ allele and homozygous +49 A/A genotype have higher levels of CTLA-4 mRNA and protein [27]. The possible 
association between CTLA-4 SNPs and cytokine levels remains inconclusive. Han et al. [40] reported CTLA-4 +49GG genotype is associated with lower TNF- $\alpha$ and IFN- $\gamma$. On the contrary, another study documented that type 1 diabetic patients carrying $+49 \mathrm{G}$ allele have higher levels of TNF- $\alpha$ and IFN- $\gamma$ [41].

By combining our findings in regard to the associations between immune-regulatory molecules with T2DM and/or lipid profiles, we speculate that CTLA-4, the negative regulator of immune response, may be one of the internal factors which regulate lipid metabolism and thus participate in diabetic onset and/or progression. Therefore, the distribution of CTLA-4 genotypes in diabetic patients and the corresponding associations between the genotypes with diabetic manifestations were investigated. Our results demonstrate that CTLA-4 SNPs are associated with clinical biochemical parameters. For the CTLA-4 -318 SNPs, lower serum TGs level was observed in T2DM individual carrying $\mathrm{C} / \mathrm{T}$ genotype $(P=0.019$, Table 4). Marginal significance is also identified between -318 genotypes with fasting glucose $(P=0.069)$ and $\mathrm{CHO} / \mathrm{HDL} \quad(P=0.067)$ in control subjects (Table 5). Our data also showed the significant association between CTLA-4 +49 genotypes with $\mathrm{CHO} / \mathrm{HDL}(P=0.004$, Table 5$)$ in control subjects. These results reveal the correlation between CTLA-4 SNPs and lipid parameters, suggesting CTLA-4 may be involved in lipid metabolism and affect T2DM disease progression.

The finding that CTLA-4 -318 SNPs are associated with TGs supports the study from Rau et al. [14], in which the author concluded that CTLA-4 genotype is correlated with diabetic progression such as earlier start of insulin treatment and the development of microangiopathic lesions, although this gene does not represent a major risk factor for T2DM. Despite elevated TGs are often associated with insulin resistance and T2DM, TGs and cardiovascular risks are tightly associated [42]. Excess amounts of circulatory TGs worsen microvascular and macrovascular diseases, increase glomerular injury and accelerate the progression of nephropathy in diabetic patients [43]. Therefore, TGs are considered as a significant and independent risk factor for diabetic patients to develop cardiovascular diseases and angiopathies. Collectively, CTLA- 4 may be a prognostic factor for patients in the development of microangiopathy based on its correlation with lipid metabolism, rather than contribute directly to T2DM onset. In addition, evidence has suggested the implication of CLTA-4 in energy metabolism. Patsoukis et al. [44] reported that CTLA-4 is involved in the metabolic profile of non-activated $\mathrm{T}$ cells through inhibiting glycolysis. They provide the clue that CTLA-4 mediated lipid metabolism through regulating the rate-limiting enzyme of fatty acid oxidation, carnitine palmitoyltransferase (CPT1A), and the major triacylglycerol hydroxylase adipocyte triglyceride lipase (ATGL). Although it may be premature to make solid conclusion regarding the role of CTLA-4 in lipid metabolism, it is possible that CTLA-4 SNPs is an internal factor which regulates lipid metabolism by mediating CPT1A and ATGL.

Several CTLA-4 genetic variants other than -318 $\mathrm{C} / \mathrm{T}$ and $+49 \mathrm{~A} / \mathrm{G}$, such as $-1722 \mathrm{C} / \mathrm{T},-1661 \mathrm{~A} / \mathrm{G}$, CT60 (rs3087243), CT61 (rs51157131), J031 (rsl1571302) and J027-1 (rsl1571297), are reported [32,45-50]. Except for $-318 \mathrm{C} / \mathrm{T}$ and $+49 \mathrm{~A} / \mathrm{G}$, the functions and/or effects of these SNPs are less characterized. At the best of our knowledge, among these SNPs, only one study documented the distribution of $-1722 \mathrm{~T} / \mathrm{C}$ genotypes between the control and T2DM subjects, with no significant difference identified [51].

Another interesting finding is the marginal significance between CTLA-4 +49 SNPs and ALT in the control subjects. Our results demonstrate that individuals carrying $+49^{*} \mathrm{G}$ allele have higher ALT. Despite no significant association between +49 genotypic frequencies and ALT in T2DM population was found, our results support the study from Kanno et al. [52] that primary biliary cirrhosis patients with CTLA- $4+49$ G/G genotype had higher ALT. Besides, HBV patients with CTLA- $4+49^{*}$ A allele show lower circulatory ALT [53]. Taken the above results together, it suggests that CTLA-4 SNPs may be implicated in serum ALT level and play certain roles in hepatic metabolism and diseases.

Abundant evidence indicates that CTLA-4 SNPs are implicated in autoimmune diseases and malignancy. Only very limited reports with contradictory conclusions regarding the study of CTLA-4 and T2DM are documented. Gribben et al. [54] demonstrated that CTLA-4 may be a candidate gene to confer T2DM susceptibility by mediating antigen-specific apoptosis and progressive pancreatic $\beta$-cell failure of T2DM. Nevertheless, our study echoes the conclusions from several studies that CTLA-4 does not represent a major risk factor for T2DM $[12-14,55,56]$. The discrepancy is speculated to be resulted from ethnic difference and sample size (as discussed below).

Ethnic difference may be one of factors leading to the conflicting results of gene polymorphisms, as the distribution of genetic polymorphisms in a certain gene is diverse among study subjects with different racial origins. Hence, it is intriguing to consider the distribution of the variants in CTLA-4 +49 and -318 SNPs among different ethnic populations. For addressing this issue, the frequencies of CTLA-4 SNPs 
among different ethnic populations are compared (Table 6). The prevalence of CTLA- $4+49$ A/A genotype varies among the populations, with the highest rate found in Middle East area (Turkish and Iranian Kurdish, about 62 67\%) [12,57], followed by Estonian (about 30\%) [13], and the lowest rate in Germany [14], Iranian [51], Chinese [55] and Taiwanese $(\sim 15 \%)$. While no significant association was documented between T2DM and CTLA-4 +49 SNPs, CTLA-4 is identified as a susceptible gene of T1DM in Iranian Kurdish [56] and Chinese [55], and T2DM in Iranian [51]. Interestingly, while relatively similar CTLA-4 -318 genotypic/allelic distribution are reported among Turkish, Iranian and Taiwanese populations, significant association between this SNPs and T2DM is only identified in Iranian [12,51]. This discrepancy reflected that differential genetic characteristics and possible distinct etiological/ environmental factors may be involved among ethnic populations.

Table 6. Distribution of CTLA-4 polymorphisms among different ethnic populations

\begin{tabular}{|c|c|c|c|c|c|c|c|}
\hline \multirow{2}{*}{\multicolumn{2}{|c|}{$\begin{array}{l}\text { CTLA4 +49 A/G } \\
\text { Population }\end{array}$}} & \multicolumn{3}{|c|}{ Genotype } & \multicolumn{2}{|l|}{ Allele } & \multirow[t]{3}{*}{ Reference } \\
\hline & & A/A & A/G & $\mathrm{G} / \mathrm{G}$ & G & $\mathbf{A}$ & \\
\hline \multicolumn{7}{|c|}{ Turkish } & \\
\hline 72 & T2DM & $59.7 \%$ & $33.3 \%$ & $6.9 \%$ & $23.6 \%$ & $76.4 \%$ & \multirow[t]{2}{*}{ [12] } \\
\hline 169 & Control & $66.9 \%$ & $26.6 \%$ & $6.5 \%$ & $19.8 \%$ & $80.2 \%$ & \\
\hline \multicolumn{8}{|l|}{ Estonian } \\
\hline 70 & T1DM & $27.1 \%$ & $41.4 \%$ & $31.5 \%$ & - & - & \multirow[t]{3}{*}{ [13] } \\
\hline 305 & T2DM & $31.1 \%$ & $50.0 \%$ & $18.9 \%$ & - & - & \\
\hline 252 & Control & $30.4 \%$ & $53.6 \%$ & $16.0 \%$ & - & - & \\
\hline \multicolumn{8}{|l|}{ Germany } \\
\hline 300 & T2DM & $11 \%$ & $47 \%$ & $42 \%$ & $65 \%$ & $35 \%$ & \multirow[t]{2}{*}[14]{} \\
\hline 466 & Control & $15 \%$ & $46 \%$ & $39 \%$ & $62 \%$ & $38 \%$ & \\
\hline \multicolumn{8}{|l|}{ Chinese } \\
\hline 402 & T1DM & $6.4 \%$ & $48.3 \%$ & $45.3 \%$ & $69.4 \%$ & $30.6 \%$ & \multirow[t]{3}{*}[52]{} \\
\hline 330 & T2DM & $9.4 \%$ & $51.8 \%$ & $38.8 \%$ & $64.7 \%$ & $35.3 \%$ & \\
\hline 482 & Control & $14.9 \%$ & $50.0 \%$ & $35.1 \%$ & $60.1 \%$ & $39.9 \%$ & \\
\hline \multicolumn{8}{|c|}{ Iranian Kurdish } \\
\hline 60 & T1DM & $41.7 \%$ & $53.3 \%$ & $5 \%$ & $32.5 \%$ & $67.5 \%$ & \multirow[t]{3}{*}[53]{} \\
\hline 56 & T2DM & $62.5 \%$ & $32.1 \%$ & $5 \%$ & $21.4 \%$ & $78.6 \%$ & \\
\hline 107 & Control & $62.6 \%$ & $33.6 \%$ & $3.7 \%$ & $20.6 \%$ & $79.4 \%$ & \\
\hline \multicolumn{8}{|l|}{ Iranian } \\
\hline 110 & T2DM & $8.1 \%$ & $37.8 \%$ & $54.1 \%$ & $73 \%$ & $27 \%$ & \multirow[t]{2}{*}[51]{} \\
\hline 100 & Control & $20 \%$ & $39 \%$ & $41 \%$ & $60.5 \%$ & $39.5 \%$ & \\
\hline \multicolumn{8}{|c|}{ Taiwanese } \\
\hline 278 & T2DM & $11.9 \%$ & $45.7 \%$ & $42.4 \%$ & $65.3 \%$ & $34.7 \%$ & \multirow{2}{*}{$\begin{array}{l}\text { This } \\
\text { study }\end{array}$} \\
\hline 287 & Control & $12.5 \%$ & $52.3 \%$ & $35.2 \%$ & $61.3 \%$ & $38.7 \%$ & \\
\hline \multicolumn{2}{|c|}{ CTLA4 -318 C/T } & \multicolumn{3}{|c|}{ Genotype } & \multicolumn{2}{|l|}{ Allele } & \multirow[t]{3}{*}{ Reference } \\
\hline Population & & $\mathrm{C} / \mathrm{C}$ & $\mathrm{C} / \mathrm{T}$ & $\mathrm{T} / \mathrm{T}$ & $\mathrm{C}$ & $\mathbf{T}$ & \\
\hline \multicolumn{7}{|l|}{ Turkish } & \\
\hline 72 & T2DM & $76.4 \%$ & $19.4 \%$ & $4.2 \%$ & $86.1 \%$ & $13.9 \%$ & \multirow[t]{2}{*}{ [12] } \\
\hline 169 & Control & $68.6 \%$ & $25.4 \%$ & $5.9 \%$ & $81.4 \%$ & $18.6 \%$ & \\
\hline \multicolumn{8}{|l|}{ Iranian } \\
\hline 110 & T2DM & $67.6 \%$ & $23.4 \%$ & $9 \%$ & $79.3 \%$ & $20.7 \%$ & \multirow[t]{2}{*}[51]{} \\
\hline 100 & Control & $88 \%$ & $10 \%$ & $2 \%$ & $93 \%$ & $7 \%$ & \\
\hline \multicolumn{8}{|c|}{ Taiwanese } \\
\hline 278 & T2DM & $81.7 \%$ & $17.6 \%$ & $0.7 \%$ & $90.3 \%$ & $9.7 \%$ & This \\
\hline 287 & Control & $74.9 \%$ & $23.3 \%$ & $1.7 \%$ & $86.6 \%$ & $13.4 \%$ & study \\
\hline
\end{tabular}

Sample size is another factor influencing the experimental results and leading to the possible discrepancy. As a matter of fact, we had recruited 996 study subjects in total (520 controls and 476 patients) and successfully investigated the genotypes of all the recruited subjects, hoping to draw a conclusion with higher statistical power by enlarging the sample size. Supplementary Table S1 showed the distribution of CTLA-4 genotyping among these 996 study subjects. Significant difference of CTLA-4 +49 genotypic $(P=0.014)$ and allelic $(P=0.016)$ frequencies between diabetic and control groups was identified, while neither the genotypic $(P=0.720)$ nor allelic $(P=0.870)$ distribution of CTLA-4 -318 between subject groups showed significant differences. Nevertheless, due to the availability of completed information regarding blood chemistry parameters listed in Table 1, we can only analyze the association between the genotypes/alleles and clinical parameters among 287 control and 278 patients.

In summary, this study discloses the significant association between CTLA-4 promoter genotypic distribution and lipid metabolism-related parameters although no significant association between CTLA-4 genotypes and T2DM was observed. Our results suggest that CTLA-4 may be involved in lipid metabolism and affect T2DM disease progression and/or the development of diabetic complications although this gene does not represent a major risk factor for T2DM.

\section{Supplementary Material}

Table S1. http://www.medsci.org/v15p0395s1.pdf

\section{Acknowledgements}

This work was supported by Shin Kong Wu Ho-Su Memorial Hospital (SKH-8302-102-NDR-06 and SKH-8302-103-NDR-10), Cheng Hsin General Hospital (107-30 and 107-FA06), and in part by Ministry of Science and Technology (MOST 105-2320B-241-005 and MOST 106-2314-B-010-032), Taiwan.

\section{Abbreviations}

ALT: alanine aminotransferase; ATGL: adipocyte triglyceride lipase; CHO: cholesterol; CPT1A: carnitine palmitoyltransferase; CTLA-4: cytotoxic T lymphocyte-associated antigen-4; HDL-C: high density lipoprotein-cholesterol; LDL-C: low density lipoprotein-cholesterol; PBMC: peripheral blood mononuclear cell; SNPs: single nucleotide polymerphisms; T2DM: type 2 diabetes mellitus; TGs: triglycerides. 


\section{Competing Interests}

The authors have declared that no competing interest exists.

\section{References}

1. McCarty D, Zimmet P. Diabetes 1994 to 2010: Global estimates and projections. International Diabetes Institute, Melbourne, Australia, 1994.

2. Chang $\mathrm{YH}$, Huang $\mathrm{CN}$, Shiau MY. The C-174G promoter polymorphism of the interleukin-6 (IL-6) gene that affects insulin sensitivity in Caucasians is not involved in the pathogenesis of Taiwanese type 2 diabetes mellitus. Eur Cytokine Netw. 2004; 15: 117-9.

3. Pickup JC, Mattock MB, Chusney GD, Burt D. NIDDM as a disease of the innate immune system: association of acute-phase reactants and interleukin-6 with metabolic syndrome X. Diabetologia 1997; 40: 1286-92.

4. Westendorp RG, Langermans JA, Huizinga TW, Elouali AH, Verweij CL, Boomsma DI, Vandenbroucke JP. Genetic influence on cytokine production and fatal meningococcal disease. Lancet 1997; 349: 170-3.

5. El-Far M, Isabelle $\mathrm{C}$, Chomont $\mathrm{N}$, Bourbonnière $\mathrm{M}$, Fonseca $\mathrm{S}$, Ancuta $\mathrm{P}$, et al. Down-regulation of CTLA-4 by HIV-1 Nef protein. PLoS One 2013; 8: e54295.

6. Bouqbis L, Izaabel H, Akhayat O, Pérez-Lezaun A, Calafell F, Bertranpetit J, Comas D. Association of the CTLA4 promoter region (-1661G allele) with type 1 diabetes in the South Moroccan population. Genes Immun. 2003; 4: 132-7.

7. Ghaderi A. CTLA4 gene variants in autoimmunity and cancer: a comparative review. Iran J Immunol. 2011; 8: 127-49.

8. Baniasadi V, Narain N, Goswami R, Das SN. Promoter region $-318 \mathrm{C} / \mathrm{T}$ and -1661 A/G CTLA-4 single nucleotide polymorphisms and type 1 diabetes in North Indians. Tissue Antigens 2006; 67: 383-9.

9. Douroudis K, Prans E, Kisand K, Nemvalts V, Uibo R. Cytotoxic T-lymphocyte antigen 4 gene polymorphisms are associated with latent autoimmune diabetes in adults. Clin Chim Acta 2009; 403: 226-8.

10. Saleh HM, Rohowsky N, Leski M. The CTLA4 $-819 \mathrm{C} / \mathrm{T}$ and +49 A/G dimorphisms are associated with type 1 diabetes in Egyptian children. Indian J Hum Genet. 2008; 14: 92-8.

11. Caputo M, Cerrone GE, López AP, Villalba A, Krochik GA, Cédola FN, et al. Cytotoxic T lymphocyte antigen 4 heterozygous codon $49 \mathrm{~A} / \mathrm{G}$ dimorphism is associated to latent autoimmune diabetes in adults (LADA). Autoimmunity 2005; 38: 277-81.

12. Uzer E, Dilmec F, Akkafa F, Boduroglu O, van Kuilenburg AB. Investigation of CTLA-4 and CD28 gene polymorphisms in patients with diabetes mellitus type 2 using PCR-RFLP in a Turkish population. West Indian Med J. 2010; 59: $235-40$

13. Haller K, Kisand K, Pisare H, Salur L, Laisk T, Nemvalts V, Uibo R. Insulin gene VNTR, CTLA-4 +49A/G and HLA-DOB1 alleles distinguish latent autoimmune diabetes in adults from type 1 diabetes and from type 2 diabetes group. Tissue Antigens 2007; 69: 121-7.

14. Rau $H$, Braun J, Donner $H$, Seissler J, Siegmund T. The codon 17 polymorphism of the CTLA4 gene in type 2 diabetes mellitus. J Clin Endocrinol Metab. 2001; 86: 653-5.

15. Ho KT, Shiau MY, Chang YH, Chen CM, Yang SC, Huang CN. Association of IL-4 promoter polymorphisms in Taiwanese patients with type 2 diabetes mellitus. Metabolism 2010; 59: 1717-22.

16. Lee $\mathrm{WY}$, Chang $\mathrm{YH}, \mathrm{Lo} \mathrm{MK}$, Chang $\mathrm{CP}_{\longleftarrow}$ Yang $\mathrm{SC}_{\longleftarrow}$ Yang $\mathrm{TP}_{\longleftarrow}$ et al. Polymorphisms of cytotoxic T lymphocyte-associated antigen-4 and cytokine genes in Taiwanese patients with ankylosing spondylitis. Tissue Antigens 2010; 75: 119-26.

17. He J, Usui I, Ishizuka $K$, Kanatani $Y$, Hiratani $K$, Iwata $M$, et al. Interleukin-1alpha inhibits insulin signaling with phosphorylating insulin receptor substrate-1 on serine residues in 3T3-L1 adipocytes. Mol Endocrinol. 2006; $20: 114-24$

18. Somm E, Cettour-Rose P, Asensio C, Charollais A, Klein M, Theander-Carrillo C, et al. Interleukin-1 receptor antagonist is upregulated during diet-induced obesity and regulates insulin sensitivity in rodents. Diabetologia 2006; 49: 387-93.

19. Atsumi $\mathrm{T}$, Cho $\mathrm{YR}$, Leng $\mathrm{L}$, McDonald $\mathrm{C}$, $\mathrm{Yu}$ T, Danton $\mathrm{C}$, et al. The proinflammatory cytokine macrophage migration inhibitory factor regulates glucose metabolism during systemic inflammation. J Immunol. 2007; 179: 5399-406.

20. Kang K, Reilly SM, Karabacak V, Gangl MR, Fitzgerald K, Hatano B, Lee CH. Adipocyte-derived Th2 cytokines and myeloid PPARdelta regulate macrophage polarization and insulin sensitivity. Cell Metab. 2008; 7: 485-95.

21. Chang $\mathrm{YH}$, Huang $\mathrm{CN}$, Wu CY, Shiau MY. Association of interleukin-10 A-592C and T-819C polymorphisms with type 2 diabetes mellitus. Hum Immunol. 2005; 66: 1258-63.

22. Shiau MY, Wu CY, Huang CN, Hu SW, Lin SJ, Chang YH. TNF-alpha polymorphisms and type 2 diabetes mellitus in Taiwanese patients. Tissue Antigens 2003; 61: 393-7.

23. Chang $\mathrm{YH}$, Huang $\mathrm{CN}$, Shiau MY. Association of IL-4 receptor gene polymorphisms with high density lipoprotein cholesterol. Cytokine 2012; 59: $309-12$.
24. Wells $\mathrm{AD}$, Walsh MC, Bluestone JA, Turka LA. Signaling through CD28 and CTLA-4 controls two distinct forms of T cell anergy. J Clin Invest. 2001; 108: 895-903.

25. Qi P, Ruan CP, Wang H, Zhou FG, Xu XY, Gu X, et al. CTLA-4 +49A/G polymorphism is associated with the risk but not with the progression of colorectal cancer in Chinese. Int J Colorectal Dis. 2010; 25: 39-45.

26. Ghaderi A, Yeganeh F, Kalantari T, Talei AR, Pezeshki AM, Doroudchi M, Dehaghani AS. Cytotoxic T lymphocyte antigen-4 gene in breast cancer. Breast Cancer Res Treat. 2004; 86: 1-7.

27. Ligers A, Teleshova N, Masterman T, Huang WX, Hillert J. CTLA-4 gene expression is influenced by promoter and exon 1 polymorphisms. Genes Immun. 2001; 2: 145-52.

28. Donner H, Rau H, Walfish PG, Braun J, Siegmund T, Finke R, et al. CTLA4 alanine-17 confers genetic susceptibility to Graves' disease and to type 1 diabetes mellitus. J Clin Endocrinol Metab.1997; 82: 143-6.

29. Zhang Q, Yang YM, Lv XY. Association of Graves' disease and Graves' ophthalmopathy with the polymorphisms in promoter and exon 1 of cytotoxic T lymphocyte associated antigen-4 gene. J Zhejianq Univ Sci B. 2006; 7: 887-91.

30. Pociot F, McDermott MF. Genetics of type 1 diabetes mellitus. Genes Immun. 2002; 3: 235-49.

31. Kavvoura FK, Ioannidis JP. CTLA-4 gene polymorphisms and susceptibility to type 1 diabetes mellitus: a HuGE Review and meta-analysis. Am J Epidemiol. 2005; 162: 3-16.

32. Ahmed S, Ihara K, Kanemitsu S, Nakashima H, Otsuka T, Tsuzaka K, et al. Association of CTLA-4 but not CD28 gene polymorphisms with systemic lupus erythematosus in the Japanese population. Rheumatology (Oxford) 2001; 40: 662-7.

33. Zaletel K, Krhin B, Gaberscek S, Hojker S. Thyroid autoantibody production is influenced by exon 1 and promoter CTLA-4 polymorphisms in patients with Hashimoto's thyroiditis. Int J Immunogenet. 2006; 33: 87-91.

34. Donner H, Braun I, Seidl C, Rau H, Finke R, Ventz M, et al. Codon 17 polymorphism of the cytotoxic T lymphocyte antigen 4 gene in Hashimoto's thyroiditis and Addison's disease. J Clin Endocrinol Metab. 1997; 82: 4130-2.

35. Hunt KA, McGovern DP, Kumar PJ, Ghosh S, Travis SP, Walters JR, et al. A common CTLA4 haplotype associated with coeliac disease. Eur J Hum Genet. 2005; $13: 440-4$.

36. Kosmaczewska A, Ciszak L, Bocko D, Frydecka I. Expression and functional significance of CTLA-4, a negative regulator of $\mathrm{T}$ cell activation. Arch Immunol Ther Exp. (Warsz) 2001; 49: 39-46.

37. Vaidya B, Pearce S. The emerging role of the CTLA-4 gene in autoimmune endocrinopathies. Eur J Endocrinol. 2004; 150: 619-26.

38. Wang XB, Zhao X, Giscombe R, Lefvert AK. A CTLA-4 gene polymorphism at position -318 in the promoter region affects the expression of protein. Genes Immun. 2002; 3: 233-4

39. de Reuver P, Pravica V, Hop W, Boor P, Metselaar HJ, Hutchinson IV, et al. Recipient ctla- $4+49$ G/G genotype is associated with reduced incidence of acute rejection after liver transplantation. Am J Transplant. 2003; 3: 1587-94.

40. Han Q, Duan S, Zhang G, Li Z, Li N, Zhu Q, Lv Y, et al. Associations between cytotoxic $\mathrm{T}$ lymphocyte-associated antigen-4 polymorphisms and serum tumor necrosis factor- $\alpha$ and interferon- $\gamma$ levels in patients with chronic hepatitis B virus infection. Inflamm Res. 2011; 60: 1071-8.

41. Balic I, Angel B, Codner E, Carrasco E, Pérez-Bravo F. Association of CTLA-4 polymorphisms and clinical-immunologic characteristics at onset of type 1 diabetes mellitus in children. Hum Immunol. 2009; 70: 116-20.

42. Pit'ha J, Kovář J, Blahová T. Fasting and nonfasting triglycerides in cardiovascular and other diseases. Physiol Res. 2015; 64 (Suppl 3): S323-30.

43. Rutledge JC, Ng KF, Aung $\mathrm{HH}$, Wilson DW. Role of triglyceride-rich lipoproteins in diabetic nephropathy. Nat Rev Nephrol. 2010; 6: 361-70.

44. Patsoukis N, Bardhan K, Chatterjee P, Sari D, Liu B, Bell LN, et al. PD-1 alters T-cell metabolic reprogramming by inhibiting glycolysis and promoting lipolysis and fatty acid oxidation. Nat Commun. 2015; 6: 6692

45. Heward JM, Allahabadia A, Carr-Smith J, Daykin J, Cockram CS, Gordon C, et al. No evidence for allelic association of a human CTLA-4 promoter polymorphism with autoimmune thyroid disease in either population-based case-control or family-based studies. Clin Endocrinol. (Oxf) 1998; 49: 331-4.

46. Aguilar F, Torres B, Sanchez-Roman J, Nunez-Roldan A, Gonzalez-Escribano MF. CTLA4 polymorphism in Spanish patients with systemic lupus erythematosus. Hum Immunol. 2003; 64: 936-40.

47. Chua KH, Puah SM, Chew CH, Tan SY, Lian LH. Study of the CTLA-4 gene polymorphisms in systemic lupus erythematosus (SLE) samples from Malaysia. Ann Hum Biol. 2010; 37: 274-80.

48. Lee YH, Kim YR, Ji JD, Sohn J, Song GG. Polymorphisms of the CTLA-4 exon 1 and promoter gene in systemic lupus erythematosus. Lupus 2001; 10: 601-5.

49. Liu MF, Wang CR, Lin LC, Wu CR. CTLA-4 gene polymorphism in promoter and exon-1 regions in Chinese patients with systemic lupus erythematosus. Lupus 2001; 10: 647-9.

50. Barreto M, Santos E, Ferreira R, Fesel C, Fontes MF, Pereira C, et al. Evidence for CTLA4 as a susceptibility gene for systemic lupus erythematosus. Eur J Hum Genet. 2004; 12: 620-6.

51. Kiani J, Khadempar S, Hajilooi M, Rezaei H, Keshavarzi F, Solgi G. Cytotoxic T Lymphocyte antigen-4 gene variants in type 2 diabetic patients with or without neuropathy. Iran J Allergy Asthma Immunol. 2016; 15: 220-8.

52. Kanno $\mathrm{Y}$, Rai $\mathrm{T}$, Monoe $\mathrm{K}$, Saito $\mathrm{H}$, Takahashi A, Irisawa A, Ohira $\mathrm{H}$. Possible association of cytotoxic T lymphocyte antigen-4 genetic polymorphism with 
liver damage of primary biliary cirrhosis in Japan. Fukushima J Med Sci. 2006; 52: 79-85.

53. Duan S, Zhang G, Han Q, Li Z, Liu Z, Chen J, et al. CTLA-4 exon $1+49$ polymorphism alone and in a haplotype with -318 promoter polymorphism may confer susceptibility to chronic HBV infection in Chinese Han patients. Mol Biol Rep. 2011; 38: 5125-32.

54. Gribben JG, Freeman GJ, Boussiotis VA, Rennert P, Jellis CL, Greenfield E, et al. CTLA4 mediates antigen specific apoptosis of human T cells. Proc Natl Acad Sci U S A. 1995; 92: 811-5.

55. Jin P, Xiang B, Huang G, Zhou Z. The association of cytotoxic T-lymphocyte antigen-4 $+49 \mathrm{~A} / \mathrm{G}$ and CT60 polymorphisms with type 1 diabetes and latent autoimmune diabetes in Chinese adults. J Endocrinol Invest. 2015; 38: 149-54.

56. Ahmadi S, Rostamzadeh J, Khosravi D, Shariati P, Shakiba N. Association of CTLA-4 gene 49A/G polymorphism with the incidence of type 1 diabetes mellitus in the Iranian Kurdish population. Pak J Biol Sci. 2013; 16: 1929-35.

57. Bednarczuk T, Hiromatsu Y, Fukutani T, Jazdzewski K, Miskiewicz P, Osikowska M, Nauman J. Association of cytotoxic T-lymphocyte-associated antigen-4 (CTLA-4) gene polymorphism and non-genetic factors with Graves' ophthalmopathy in European and Japanese populations. Eur J Endocrinol. 2003; 148: 13-8. 